\title{
Pentagamavunon-0 (PGV-0) Enhance Cytotoxic Effect of Doxorubicin Through Increasing of Apoptosis, Senescence and ROS Level on Triple Negative Breast Cancer 4T1
}

\author{
Ismanurrahman Hadi ${ }^{1,2}$, Riris Istighfari Jenie ${ }^{2,3}$, Edy Meiyanto ${ }^{2,3^{*}}$ \\ 'Magister Program of Pharmacy, Faculty of Pharmacy, Universitas Gadjah Mada, Indonesia \\ ${ }^{2}$ Cancer Chemoprevention Research Center, Faculty of Pharmacy, Universitas Gadjah Mada, Indonesia \\ ${ }^{3}$ Department of Pharmaceutical Chemistry, Faculty of Pharmacy, Universitas Gadjah Mada, Indonesia
}

\begin{abstract}
Triple negative breast cancer (TNBC), one of the sub type of breast cancers was widely known with high tumorigenic and poor prognosis than others. The development of combination agent (co-chemotherapy) with doxorubicin for chemotherapy of TNBC were carried out to decrease doxorubicin side effect and resistance in cancer. This present study aims to explore the co-chemotherapeutic properties of Pentagamavunon-0 (PGV-0) and investigate induction of doxorubicin on apoptosis, senescence and Reactive Oxygen Species (ROS) against TNBC. 4T1 Cell line was used as a TNBC in vitro model. Cytotoxic measurement was performed using 3-(4,5-dimetiltiazol-2-il)-2,5-difeniltetrazolium bromide (MTT) assay resulting in $\mathrm{IC}_{50}$ values of $52 \mu \mathrm{M}$. Meanwhile, the combination of doxorubicin and PGV-0 showed synergistic effect which decreased cell viability of $4 \mathrm{~T} 1$ better than single treatment of doxorubicin. Apoptosis analysis was performed using annexin V/PI assay indicated that the combination treatment of PGV-0 and doxorubicin increased apoptosis evidence. Senescence detection was carried out using senescence-associated- $B$ galactosidase (SA-B-GAL) assay. The results showed that a single treatment of PGV-0 induced cellular senescence and increased senescence cells in combination treatment. Moreover, 2',7'-dichlorofluorescein diacetate (DCFDA) staining showed that PGV-0 increased ROS level at single treatment, whereas combination treatment increased ROS intracellular compared to the positive control of doxorubicin. Based on these results, PGV-0 has potential as a co-chemotherapeutic candidate on TNBC.
\end{abstract}

Keyword: 4T1, PGV-0, Co-chemotherapy, Cytotoxic, Senescence, Apoptosis, ROS

\section{INTRODUCTION}

Triple negative breast cancer (TNBC), one of the highly tumorigenic of breast cancers is known as difficult to treat due to the lacking of estrogen receptor, progesterone receptor and human epidermal receptor-2 (HER-2) (O'Reilly, et al., 2015). TNBC chemotherapy uses doxorubicin with a broad spectrum of action. Nevertheless, long term usage of doxorubicin can cause side effects such as cardiotoxicity and resistance of doxorubicin in cancer (Hanna, et al., 2014). The

Submitted: October 21, 2019

Revised: December 9, 2019

Accepted: December 10, 2019

*Corresponding author: edy_meiyanto@ugm.ac.id 
recent development of TNBC chemotherapy directed to find a potential combination agent (cochemotherapy) that can increase the effectiveness of doxorubicin. In this regard, doxorubicin is hopefully to forms a synergistic effect with cochemotherapeutic agents which results in enhancing the cytotoxic effect of doxorubicin, thus decreasing the dose of doxorubicin to reduce the side effect and avoid the cancer cell resistance to doxorubicin.

Curcumin, a phenolic compound of turmeric (Curcuma longa) is known to have cytotoxic properties by targeting various proteins involved in cell survival, metastasis, and angiogenesis. A study reported that curcumin also increases Reactive Oxygen Species (ROS) level through interaction with ROS metabolism enzymes such as glutathione S-transferase and Nicotinamide Adenine Dinucleotide Phosphate Hydrogen (NAD $(\mathrm{P}) \mathrm{H})$ dehydrogenase (Larasati, et al., 2018). The increase of ROS intracellular over cellular capacity tolerance of ROS could trigger senescence, a kind of cell cycle arrest that limits the replicative capacity of cells and induce apoptosis resulting in inhibition of the progression of cancer (Campisi, 2013). As co-chemotherapeutic agents, the combination of curcumin with doxorubicin enhances the cytotoxicity of doxorubicin in cancer through inhibition of efflux transporters which responsible for doxorubicin resistance (Tan and Norhaizan, 2019; Wen, et al., 2019). However, curcumin has low bioavailability that reduces the cytotoxic effect on in vivo study. Therefore, the development of curcumin analogs was carried out to find more potent compounds than curcumin.

Pentagamavunon-0 (PGV-0), one of the curcumin analogs was synthesized using vanillin and cyclopentanone. PGV-0 exhibits cytotoxic properties against several types of breast cancer such as T47D, Michigan Cancer Foundation-7 (MCF-7), and MCF-7/Dox (Da'i, et al., 2012; Meiyanto, et al., 2014). The previous study reported that a combination of $\mathrm{PGV}-0$ and doxorubicin showed an increase of cytotoxic and sensitivity effect of doxorubicin on MCF-7/Dox due to HER2 with $\mathrm{PgP}$ inhibition and activation in the nuclear factor kappa-light-chain-enhancer of activated $\mathrm{B}$ cells (NF-kB) pathway (Meiyanto, et al., 2014). This present study aims to reveal the potential cochemotherapeutic effect of PGV-0 on 4T1 cells, as a model of TNBC. Furthermore, this study also investigates its effect on apoptosis, cellular senescence, and ROS level. The result of this study can be used as a foundation of a further experiment for the development of PGV-0 for TNBC.

\section{MATERIAL AND METHOD}

\section{Chemical Material}

PGV-0 compound was obtained from Cancer Chemoprevention Research Center (CCRC), faculty of Pharmacy, Universitas Gadjah Mada. Doxorubicin was obtained from Wako Pure Chemical Industries, Ltd (Osaka, Japan).

\section{Cell Culture}

Cell line vero and cell line 4T1 (ATCCRCRL-2539TM) were obtained from Prof. Masashi Kawaichi, MD., Ph.D (Nara Institute of Science and Technology, NAIST, Nara, Japan). Cell cultured on high glucose Dulbecco's Modified Eagles Medium (DMEM) (Gibco, New York, USA) supplemented with 10\% Fetal Bovine Serum (FBS) (SigmaAldrich, Missouri, USA) and $1.5 \%$ penicillinstreptomycin (Gibco) (V/v) (Gibco) and then incubated at $37^{\circ} \mathrm{C}$ with $5 \% \mathrm{CO}_{2}$. Cells were harvested from tissue culture disk (Iwaki, Tokyo, Japan) using $0.25 \%$ trypsin-Ethylenediaminetetraacetic acid (EDTA) (Gibco).

\section{Cytotoxic Assay}

Cytotoxic assay was performed by 3-(4,5-dimetiltiazol-2-il)-2,5-difeniltetrazolium bromide (MTT) cell viability assay (Mosmann, $1983)$. The $4 \mathrm{~T} 1$ cell line $\left(2.65 \times 10^{3}\right.$ cell/well $)$ and Vero cell $\left(1 \times 10^{4}\right.$ cell/well $)$ were cultured at $96-$ well plate. The cells were treated with various concentrations of PGV-0 and incubated in $\mathrm{CO}_{2}$ incubator for $24 \mathrm{~h}$ at $37^{\circ} \mathrm{C}$. After $24 \mathrm{~h}$, culture media 
were removed and cells washed using Phosphatebuffered saline (PBS) IX. A total of $100 \mu \mathrm{L} /$ well 3-(4,5-dimetiltiazol-2-il)-2,5-difeniltetrazolium bromide (MTT) solution $(0.5 \mathrm{mg} / \mathrm{mL})$ (Biovision, California, USA) were added. If formazan has been formed, a 10\% Sodium Dodecyl Sulphate (SDS) solution $(100 \mu \mathrm{L} /$ well $)$ was added then incubated overnight under room temperature. Absorbance measured using a microplate reader (BioRad, California, USA) at $595 \mathrm{~nm}$. The value of $\mathrm{IC}_{50}$ was calculated using linearity regression of cell viability, while its value was used to analyze the selectivity index (SI) of PGV-0. The value of $\mathrm{SI}>2$ indicated that PGV-0 selective on 4T1 (Koch, et al., 2005).

\section{Combination Cytotoxic Assay}

Cytotoxic combination assay was performed using modified of MTT cell viability assay that described on previous study of PGV0 (Meiyanto, et al., 2014). The 4T1 cell line $\left(2.65 \times 10^{3}\right.$ cell/well $)$ were cultured at 96 -well plate and treated with combination of PGV-0 $(12.5 \mu \mathrm{M}$, $25 \mu \mathrm{M}$, and $50 \mu \mathrm{M})$ and doxorubicin (10 $\mathrm{nM}$ and $100 \mathrm{nM})$ in culture medium (100 $\mu \mathrm{L} /$ well). After 24 $\mathrm{h}$ incubation on $\mathrm{CO}_{2}$ incubator at $37^{\circ} \mathrm{C}$, cells were washed using PBS IX and $100 \mu \mathrm{L}$ MTT solution $(0.5 \mathrm{mg} / \mathrm{mL})$ (Biovision) was added each well. A total of $100 \mu \mathrm{L} /$ well SDS solution (10\%) added to stop the formazan forming reaction. The cells were incubated overnight under room temperature. Absorbance measured using a microplate reader (BioRad) at $595 \mathrm{~nm}$. The calculation of combination index (CI) was carried out to analyze combination effect of doxorubicin and PGV-0. The value of CI used to determine combination effect of both compound, whether synergistic $(\mathrm{CI}<0.9)$, additive (CI:0.9-1) or antagonistic (CI >1.1) (Huang, et al., 2017).

\section{Annexin V/PI Staining (Apoptosis Assay)}

A total of $4 \mathrm{~T} 11.5 \times 10^{6}$ cells/well were cultured at 6 -well plate. The cells were treated with PGV-0 at a concentration of $50 \mu \mathrm{M}$ and combination with doxorubicin $(10 \mathrm{nM}$ and 100
$\mathrm{nM})$. Treated cells were incubated for $24 \mathrm{~h}$ at $37^{\circ} \mathrm{C}$ and $5 \% \mathrm{CO}_{2}$. Cells were harvested using $0.25 \%$ EDTA and collected at microtube. The cells were fixed using cold ethanol $(70 \%)$ for 30 minutes. After that, ethanol was removed from cells suspense, then added a solution of annexin V/PI (Roche, Hague Rd, Indianapolis, USA) $50 \mu \mathrm{g} / \mathrm{mL}$ in binding buffer. Cells suspension was incubated in a $\mathrm{CO}_{2}$ incubator for 10 minutes at $37^{\circ} \mathrm{C}$. Apoptosis assay was performed using BD Accury C-6 Flowcytometer at $488 \mathrm{~nm}$. Data were presented as a percentage of early apoptosis, late apoptosis, and necrosis (Lakshmanan and Batra, 2013).

\section{Senescence-Associated $\beta$-Galactosidase (SA- $\beta$-GAL) Assay}

The 4T1 $\left(1.5 \times 10^{6}\right.$ cell/well $)$ were cultured at a 6-well plate. After $24 \mathrm{~h}$ incubation, medium culture was removed and the cells washed using $1 \mathrm{X}$ PBS. The cells were treated using PGV0 singly $(25 \mu \mathrm{M}$ and $50 \mu \mathrm{M})$ and combination with doxorubicin at concentration $10 \mathrm{nM}$. Cells were incubated at $\mathrm{CO}_{2}$ incubator for $24 \mathrm{~h}, 37^{\circ} \mathrm{C}$. After that, the cells were fixed with paraformaldehyde (PFA) 4\% for 10 minutes at room temperature, and then washed twice using 1X PBS. Each well given $1 \mathrm{~mL}$ of Senescence-Associated $\beta$-Galactosidase (SA- $\beta$-GAL) dye solutions and incubated in incubator non- $\mathrm{CO}_{2}$ at $37^{\circ} \mathrm{C}$. The cells were observed at 24, 48 and $72 \mathrm{~h}$ using an inverted microscope. The senescence cell was distinguished with blue-greenish color. Data were presented as the percentage of senescence cell (Eccles and Li, 2012).

\section{Analysis of Intracellular Reactive Oxygen Species (ROS) Using 2', 7' -dichlorofluorescein diacetate (DCFDA) Staining}

The 4T1 cell line $\left(5 \times 10^{4}\right.$ cell/well $)$ were cultured in culture media (DMEM) at 24-well plate. The cells harvested using $300 \mu \mathrm{L}$ trypsinEDTA. Trypsin was inactivated using $500 \mu \mathrm{L}$ supplemented buffer and collected at microtube. A total of $25 \mu \mathrm{M}$ DCFDA solutions were given each well. Cells were incubated in $\mathrm{CO}_{2}$ incubator, for 30 
minutes at $37^{\circ} \mathrm{C}$. After that, cells were treated with PGV-0 at concentration $50 \mu \mathrm{M}$ and its combination with doxorubicin $10 \mathrm{nM}$. After 30 minutes of incubation, ROS analysis was performed using BD Accury C-6 Flowcytometer at $458 \mathrm{~nm} / 535 \mathrm{~nm}$. Mean fluorescence intensity was used to determine the ROS level on cells (Eruslanov and Kusmartsev, 2010).

\section{RESULTS}

\section{Cytotoxic Effect of PGV-0}

Several studies of PGV-0 revealed cytotoxic properties of PGV-0 on various types of breast cancer (Hermawan, et al., 2011; Meiyanto, et al., 2014). Nevertheless, the cytotoxic effect of PGV-0 on TNBC is not yet known. Therefore, we examine cytotoxic properties of PGV-0 on TNBC using a 4T1 cell line as a TNBC model and a Vero cell line as a normal cell. This research showed that PGV-0 has a cytotoxic effect on dose-dependent manner with $\mathrm{IC}_{50}$ values of $4 \mathrm{~T} 1$ cells and vero cells were each $52 \mu \mathrm{M}$ and $152 \mu \mathrm{M}$ (Figure 1). The analysis of selectivity indicated that the cytotoxic effect of PGV-0 was selective on 4T1 cells (SI>2).

\section{Cytotoxic Combination of PGV-0 with Doxorubicin}

Based on the cytotoxic data above, PGV-0 showed great potential as an anticancer compound. We assumed that the inhibitory effect of PGV0 was possibly enhancing the cytotoxic effect of doxorubicin on $4 \mathrm{~T} 1$ cells. In this experiment, we investigate the cytotoxic effect of PGV-0 on 4T1 in combination with doxorubicin. We used PGV-0 at $12.5 \mu \mathrm{M}, 25 \mu \mathrm{M}$, and $50 \mu \mathrm{M}$ combined with doxorubicin at the concentration of $10 \mathrm{nM}$ and 100 $\mathrm{nM}$. The results of combination treatment (Figure 2) were reduced cell viability of 4T1 cells higher than single treatment of doxorubicin or PGV-0. The combination index value of each concentration less than 0.9 indicated a synergistic effect on 4T1 cells (Table 1). This data suggested that the cytotoxic effect of combination treatment is greater than the sum of each effect on a single treatment.

\section{Apoptosis Induction Effect of Combination Doxorubicin and PGV-0}

The combination of PGV-0 and doxorubicin resulted in improved cytotoxicity of doxorubicin on $4 \mathrm{~T} 1$ cells. To confirm the cellular mechanism of these combinatorial treatments, we performed apoptosis analysis using annexin V/PI assay. The results show that PGV-0 at concentration $50 \mu \mathrm{M}$ induces apoptosis on $4 \mathrm{~T} 1$ cells, while combination treatment increase apoptosis effect was better than single treatment of PGV-0 or doxorubicin (Figure 3 and Table 2). However, looking at the data of
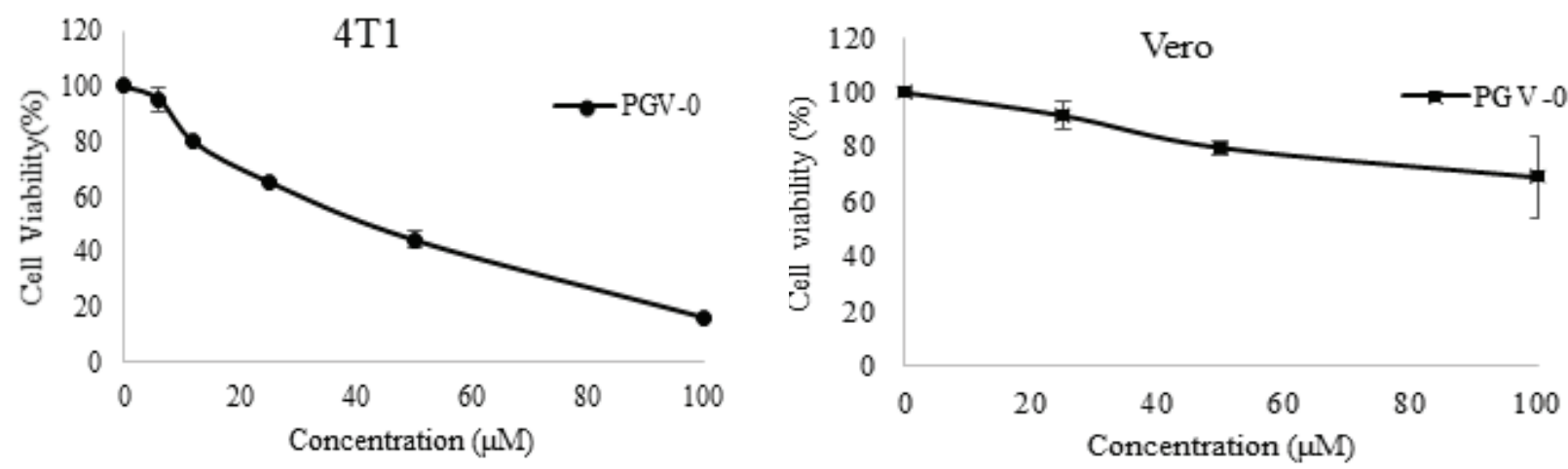

Figure 1. Cytotoxicity of PGV-0 on 4T1 and Vero cells. The 4T1 cells $\left(2.6 \times 10^{3}\right.$ cell/well) and Vero $\left(1 \times 10^{4}\right.$ cell/ well) were cultured at 96 well-plate, then treated with various concentration of PGV-0. After $24 \mathrm{~h}$ incubation, MTT solutions were added. SDS were given to stop formazan forming reaction, then incubated overnight. The $\mathrm{IC}_{50}$ values was calculated from the triplicate experiments $(A)$ cytotoxic effect of PGV-0 on 4T1, (B) cytotoxic effect of PGV-0 on Vero cell line. 


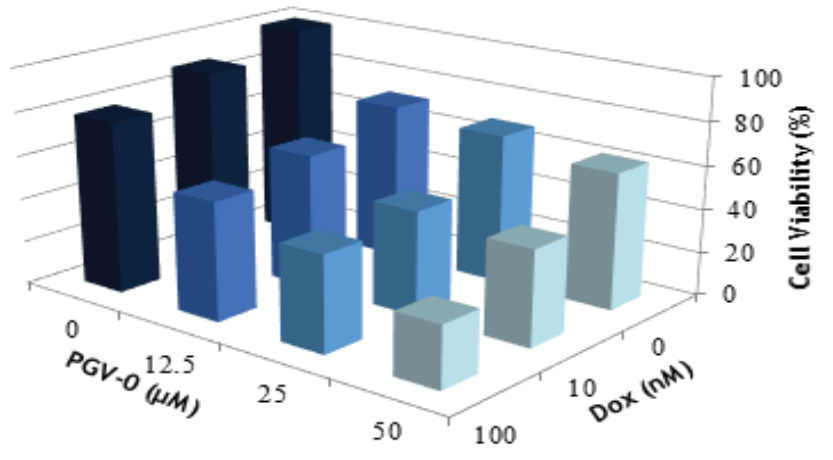

Figure 2. Cytotoxicity of Combination and single treatment on 4T1 cells. The 4T1 Cells $\left(2.65 \times 10^{3}\right.$ cell/well $)$ were treated with combination of PGV-0 and doxorubicin (Dox) as described in the material and methods. After incubated for $24 \mathrm{~h}$, the cells viability were measured using MTT assay.

cytotoxic assay, the data of single treatment PGV-0 $(50 \mu \mathrm{M})$ of this experiment has higher death cells. We suspect this biased data may be occurred due to results of a long exposure of trypsin which resulted in leakage of cell metabolites (Bundscherer, et al., 2013). Regardless of these results, these data still give information that a combination of PGV-0 and doxorubicin may affect the apoptosis mechanism of doxorubicin on 4T1 cells.

\section{Senescence Induction Effect of Combination PGV-0 and Doxorubicin}

Besides apoptosis, another cellular mechanism that could be induced by anticancer compounds was senescence. Doxorubicin were known induce cellular senescence on cells. Therefore, these combinatioral treatment possibly affect senescence on 4T1. We were used SA- $\beta$ GAL assay to determine senescence cells. The senescence cells were identified by blue-greenish color to cellular senescence, while the untreated cells is given no change of color. Observation using an inverted microscope detected cellular senescence within single and combination treatment (Figure 4). Single treatment of PGV-0 at concentration $25 \mu \mathrm{M}$ and $50 \mu \mathrm{M}$ showed that PGV-0 induce senescence each $2.03 \%$ and $3.13 \%$ on $4 \mathrm{~T} 1$ cells. Meanwhile, combination treatment were exhibit senescence cells each $6.99 \%$ and $7.70 \%$ higher than single treatment of doxorubicin $10 \mathrm{nM}(3.33 \%)$. These data suggested that administration of PGV-0 could enhance senescence effect of doxorubicin on $4 \mathrm{~T} 1$.

\section{ROS Level of Single Treatment PGV-0 and Its Combination}

The increase of apoptosis and senescence corresponding to an increase of cellular stress. The cancer cells has higher level of ROS compared with normal cells. However, an increase of ROS level could lead to oxydative stress which lead to both apoptosis and senescence. The combination of PGV0 and doxorubicin may be increased ROS level on 4T1. Therefore to confirm these assumption, we also investigate ROS level on 4T1 cells. We were performed DCFDA staining assay to quantify ROS level on the 4T1 cells. The ROS level was calculated from fluorescence intensity given by the presence of DCF-fluorescence accumulated on cells. The single treatment of PGV-0 or doxorubicin increase ROS level, while combination of both compounds increases ROS level higher on 4T1 cells (Figure 5).

Table 1. Combination index $(\mathrm{Cl})$ analysis of doxorubicin with PGV-0. $\mathrm{Cl}$ was used to determine interaction between each compound in combination treatment. Synergistic effect determined with $\mathrm{Cl}$ value $<0.9$.

\begin{tabular}{ccc}
\hline PGV -0 & \multicolumn{2}{c}{ DOX (nM) } \\
\cline { 2 - 3 }$(\mu \mathrm{M})$ & 10 & 100 \\
\hline 12.5 & 0.34 & 0.27 \\
25 & 0.46 & 0.42 \\
50 & 0.84 & 0.63 \\
\hline
\end{tabular}


Hadi, et al., 2020

Indones. J. Cancer Chemoprevent., 11(1), 7-15

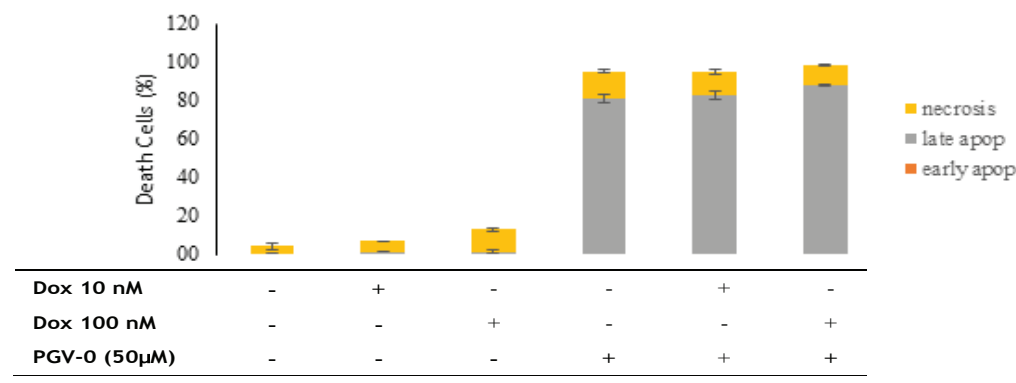

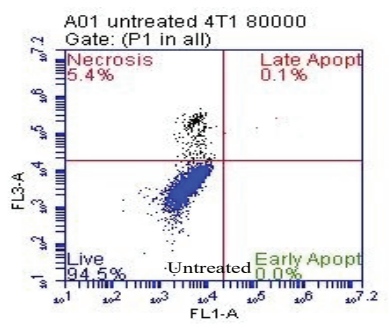

Untreated

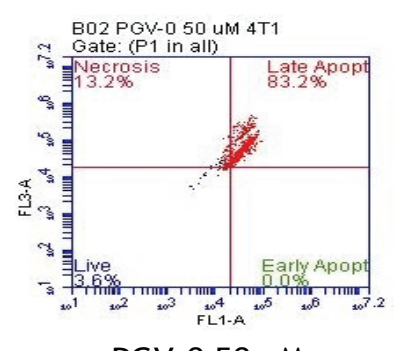

PGV-0 $50 \mu \mathrm{M}$

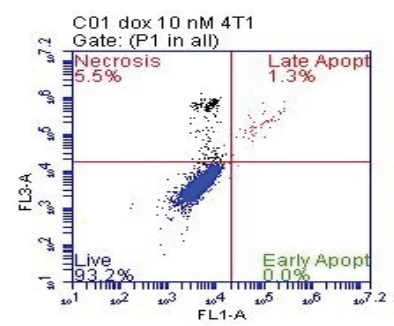

Dox $10 \mathrm{nM}$

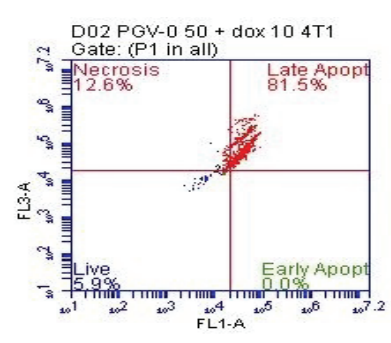

PGV-0 $50 \mu \mathrm{M}+$ dox 10

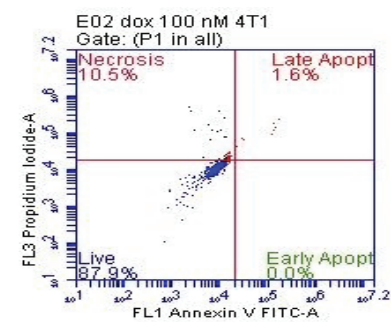

Dox $100 \mathrm{nM}$

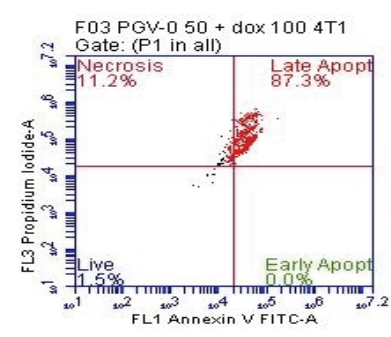

PGV-0 $50 \mu M+$ dox 100

Figure 3. Apoptosis effect of PGV-0, doxorubicin and combination of both compound on 4T1 cells. Cells were treated with single treatment and combination of PGV-0 and doxorubicin. Treated cells were harvested and collected at microtube, then stained using annexin V/PI. The cells were analysed using flowcytometry (A). Quantification cell death in each group (B). Quadrant analysis of cells on flowcytometry.

Table 2. Quantification of apoptosis and necrosis using annexin V/PI staining.

\begin{tabular}{|c|c|c|c|}
\hline Group & Early apoptosis (\%) & Late apoptosis (\%) & Necrosis (\%) \\
\hline Untreated & 0.0 & 0.0 & 4.0 \\
\hline Dox $10 \mathrm{nM}$ & 0.0 & 1.3 & 5.5 \\
\hline Dox $100 \mathrm{nM}$ & 0.0 & 1.4 & 11.3 \\
\hline PGV-O $(50 \mu M)$ & 0.0 & 80.8 & 14.4 \\
\hline PGV-O $(50 \mu M)+$ dox 10 & 0.0 & 82.8 & 11.8 \\
\hline PGV-O $(50 \mu M)+\operatorname{dox} 100$ & 0.0 & 88.0 & 10.2 \\
\hline
\end{tabular}


Indonesian Journal of Cancer Chemoprevention, February 2020

ISSN: 2088-0197

e-ISSN: 2355-8989

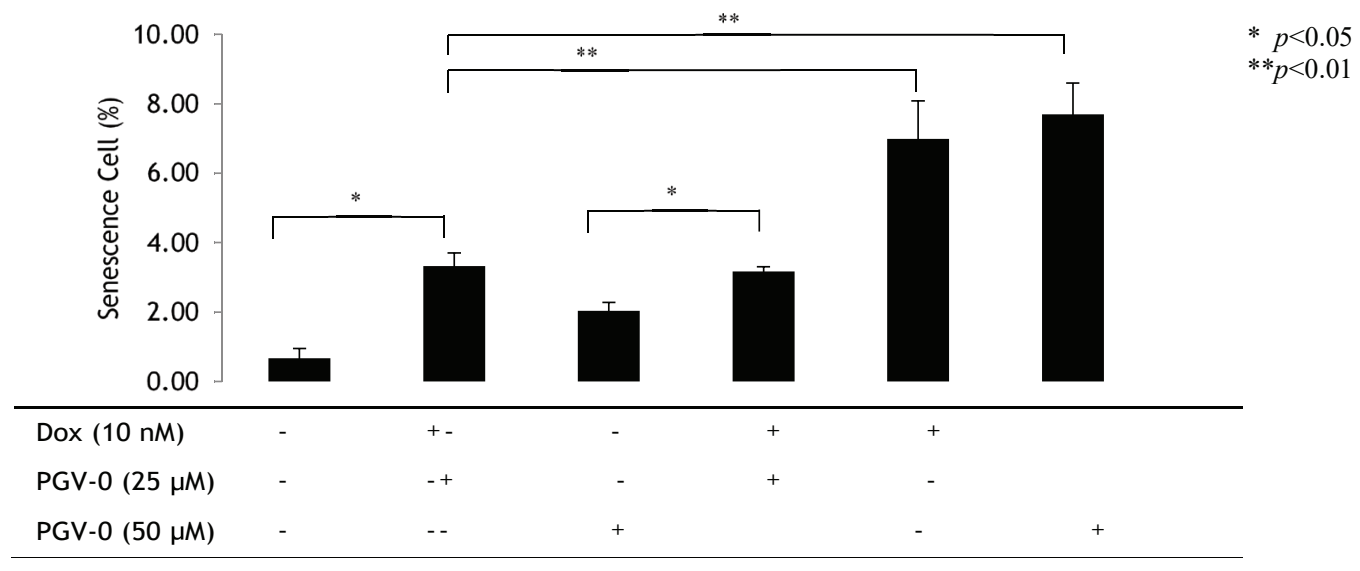

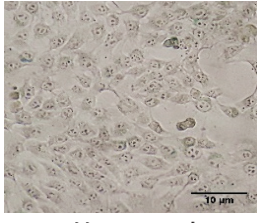

Untreated

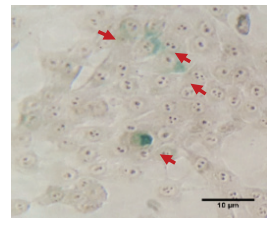

Dox10 nM

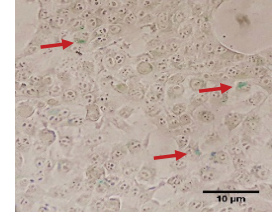

PGV-0 25

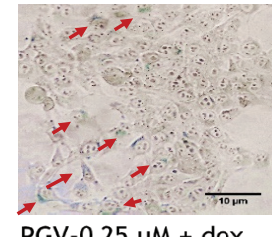

PGV-0 $25 \mu \mathrm{M}+$ dox

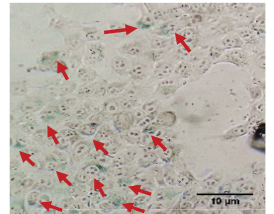

PGV-0 $50 \mu \mathrm{M}$

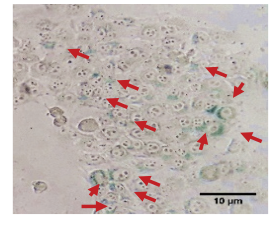

PGV-0 $50 \mu \mathrm{M}+$ dox

Figure 4. Senescence induction effect of PGV-0 singly and combination with doxorubicin. The 4T1 cell line $\left(1.5 \times 10^{6}\right.$ Cell/well) treated with single treatment of PGV-0 and combination with $10 \mathrm{nM}$ doxorubicin. SA-B -GAL dye was given after $24 \mathrm{~h}$ treatment. Cellular senescence observed at 24,48 and $72 \mathrm{~h}$. (A) percentage of cellular senescence $\left(n=3,{ }^{*}=p<0.05,{ }^{* *}=p<0.01\right)(B)$. Morphology of cell after $72 \mathrm{~h}$ staining (scale bars $\left.=10 \mu \mathrm{m}\right)$. Inverted microscope was used to observed cellular senescence (200X).

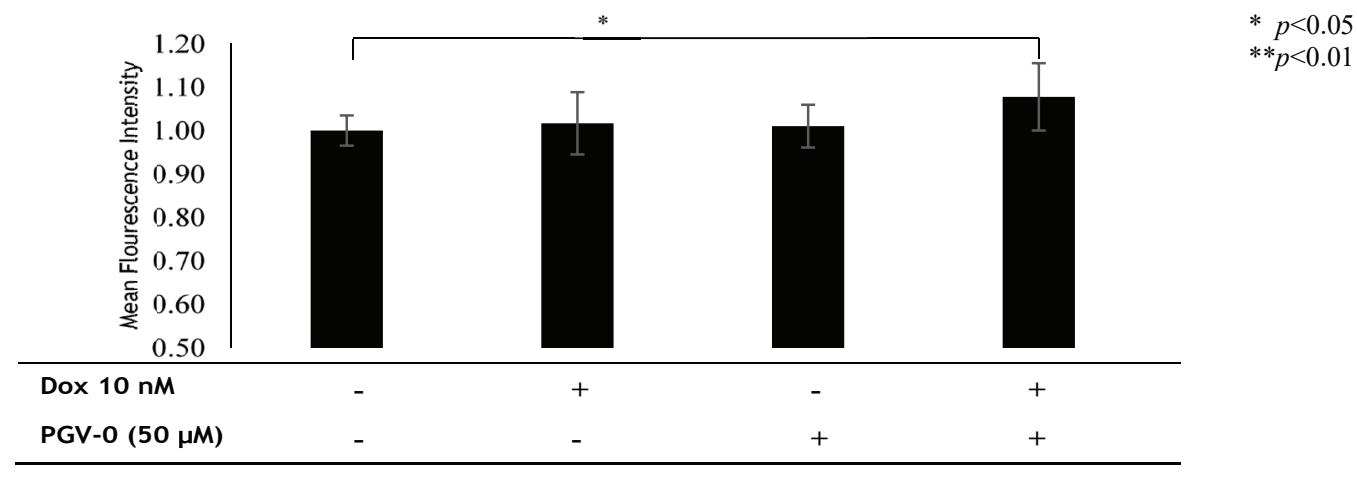

Figure 5. ROS level of 4T1 single treatment and combination PGV-0. Cells 4T1 culture (5x104 cell/well) were trypsinized and collected at microtube, then inactivated using supplemented buffer. DCFDA reagent $(25 \mu \mathrm{M})$ were added to suspension cell. After that, suspension cells were treated with PGV-0 singly and its combination. After $4 \mathrm{~h}$ incubation, intensity ROS fluorescence analysed using flowcytometry instrument $\left({ }^{*}=p<0.05^{* *}=p<0.01\right)$. 


\section{DISCUSSION}

Doxorubicin has strong anticancer properties against breast cancer, thus making its usage more preferred for chemotherapy especially for TNBC (O'Reilly, et al., 2015). However, long term use of doxorubicin was restricted due to the adverse effect and risk of doxorubicin's resistance. Therefore, the exploration of co-chemotherapeutic agents urgently needed to improve the cytotoxicity of doxorubicin against cancer. This study aimed to explore the co-chemotherapeutic properties of PGV-0 on 4T1 cells as an in vitro model for TNBC.

PGV-0 compound is one of the potential curcumin analogs to be developed to improve the cytotoxicity of doxorubicin. Previously, PGV-0 reported form synergistic effect with doxorubicin which enhances the sensitivity of doxorubicin on MCF-7 resistance doxorubicin (MCF-7/Dox) (Meiyanto, et al., 2014). In this present study, we found that PGV-0 form synergistic effect which enhances the cytotoxicity of doxorubicin on 4T1 cells. Interestingly, investigation on cellular mechanism shows that PGV-0 also increases induction effects of doxorubicin on senescence, ROS and possibly apoptosis. Considering those data, it is likely that the inhibitory effect of PGV-0 may be correlated with the increase of oxidative stress through a higher level of ROS on 4T1 cells. Several studies reported that an increase of ROS over cellular threshold could trigger activation pathways of senescence and apoptosis, which led to the inducing of apoptosis and senescence on cells (Davalli, et al., 2016; Redza-Dutordoir and Averill-Bates, 2016). Taken those finding above, PGV-0 may enhance the cytotoxicity of doxorubicin through the increase of the ROS intracellular level. Nevertheless, the molecular mechanism of PGV-0 remains undiscovered yet. Further investigation is needed to prove this hypothesis as well as revealed the mechanism molecular of PGV-0.

\section{CONCLUSION}

Analog curcumin PGV-0 potential to be developed as a co-chemotherapeutic agent with doxorubicin against TNBC.

\section{REFERENCES}

Bundscherer, A., Malsy, M., Lange, R., Hofmann, P., Metterlein, T., Graf, B.M. and Gruber, M., 2013, Cell Harvesting Method Influences Results of Apoptosis Analysis by Annexin V Staining, Anticancer Res., 33, 3201-3204.

Campisi, J., 2013, Aging, Cellular Senescence, and Cancer, Annu. Rev. Physiol., 75, 685-705.

Da'i, M., Jenie, U.A., Am, S., Meiyanto, E. and Kawaichi, M., 2012, The Effect of PGV-1, PGV-0 and Curcumin on Protein Involve in G2-M Phase of Cell Cycle and Apoptosis on T47D Breast Cancer Cell Line, J. Ilmu Kefarmasian Indonesia, 10, 99-110.

Davalli, P., Mitic, T., Caporali, A., Lauriola, A. and D'Arca, D., 2016, ROS, Cell Senescence, and Novel Molecular Mechanisms in Aging and Age-Related Diseases, Oxid. Med. Cell. Longev., 2016, 1-18.

Eccles, M. and Li, C.G., 2012, Senescence Associated B-galactosidase Staining, Bio-Protoc., 2, e247.

Eruslanov, E. and Kusmartsev, S., 2010, Identification of ROS using oxidized DCFDA and flow-cytometry, Methods Mol. Biol. Clifton NJ, 594, 57-72.

Hanna, A.D., Lam, A., Tham, S., Dulhunty, A.F. and Beard, N.A., 2014, Adverse Effects of Doxorubicin and Its Metabolic Product on Cardiac RyR2 and SERCA2A, Mol. Pharmacol., 86, 438-449.

Hermawan, A., Aditya, F., Sendy, J. and Muthi, I., 2011, PGV-0 And PGV-1 Increased Apoptosis Induction of Doxorubicin on MCF-7 breast Cancer Cells, Pharmacon, 12, 5.

Huang, L., Jiang, Y. and Chen, Y., 2017, Predicting Drug Combination Index and Simulating the 
Network-Regulation Dynamics by Mathematical Modeling of Drug-Targeted EGFR-ERK Signaling Pathway, Sci. Rep., 7, 40752.

Koch, A., Tamez, P., Pezzuto, J. and Soejarto, D., 2005, Evaluation of plants used for antimalarial treatment by the Maasai of Kenya, J. Ethnopharmacol., 101, 95-99.

Lakshmanan, I. and Batra, S.K., 2013, Protocol for Apoptosis Assay by Flow Cytometry Using Annexin V Staining Method, Bio-Protoc., 3.

Larasati, Y.A., Yoneda-Kato, N., Nakamae, I., Yokoyama, T., Meiyanto, E. and Kato, J., 2018, Curcumin targets multiple enzymes involved in the ROS metabolic pathway to suppress tumor cell growth, Sci. Rep., 8, 2039.

Meiyanto, E., Putri, D.D.P., Susidarti, R.A., Murwanti, R., Sardjiman, Fitriasari, A., Husnaa, U., Purnomo, H. and Kawaichi, M., 2014, Curcumin and its analogues (PGV-O and PGV-1) enhance sensitivity of resistant MCF-7 cells to doxorubicin through inhibition of HER2 and NF-kB activation, Asian Pac. J. Cancer Prev. APJCP, 15, 179-184.
Mosmann, T., 1983, Rapid colorimetric assay for cellular growth and survival: Application to proliferation and cytotoxicity assays, J. Immunol. Methods, 65, 55-63.

O'Reilly, E.A., Gubbins, L., Sharma, S., Tully, R., Guang, M.H.Z., Weiner-Gorzel, K., McCaffrey, J., Harrison, M., Furlong, F., Kell, M. and MCCann, A., 2015, The fate of chemoresistance in triple negative breast cancer (TNBC), BBA Clin., 3, 257-275.

Redza-Dutordoir, M. and Averill-Bates, D.A., 2016, Activation of apoptosis signalling pathways by reactive oxygen species. Biochim. Biophys, Acta BBA-Mol. Cell Res., 1863, 2977-2992.

Tan, B.L. and Norhaizan, M.E., 2019, Curcumin Combination Chemotherapy: The Implication and Efficacy in Cancer, Molecules, 24, 2527.

Wen, C., Fu, L., Huang, J., Dai, Y., Wang, B., Xu, G., Wu, L. and Zhou, H., 2019, Curcumin reverses doxorubicin resistance via inhibition the efflux function of $A B C B 4$ in doxorubicin-resistant breast cancer cells, Mol. Med. Rep., 19, 5162-5168. 